\title{
Postprandial Plasma Glucose, Insulin, Glucagon and Triglyceride Responses to a Standard Diet in Normal Subjects
}

\author{
M. Ahmed, M.C. Gannon and F.Q. Nuttall \\ The Metabolic Section, Veterans Administration Hospital and the Univ. of Minnesota Medical School, Minneapolis, Minnesota, USA
}

Summary. Postprandial plasma glucose, insulin and triglyceride responses were determined in 12 normal subjects ( 7 male and 5 female) fed a standard diet composed of typical American foods; the three meals were identical for each subject. A significant postprandial rise in glucose and insulin was observed. They were closely related temporally in the early postabsorptive period. However, in the late post-absorptive phase insulin decline was generally slower than the glucose decline. A considerable difference in the glucose and insulin response was observed between males and females. Fasting plasma glucose and insulin concentrations were lower in the women. Following each meal the peak plasma glucose was lower in the women, but the difference was significant only following breakfast $(\mathrm{p}<0.02)$. The area under the glucose curve following breakfast was also lower $(p<0.01)$ in the women. In the men the maximal postprandial glucose concentration and the postprandial glucose area remained stable throughout the day, but there was an increase in peak insulin concentration and insulin area after dinner. In contrast, in the women the maximal postprandial glucose concentration and the postprandial glucose area increased throughout the day, but the peak insulin concentration and insulin area did not change. Plasma triglycerides increased with breakfast and remained elevated throughout the day. Both fasting and postprandial mean triglycerides were higher in the men, but this did not reach statistical significance. The circulating pancreatic glucagon concentration, determined in 4 subjects, was unaffected by meals and remained stable throughout the day.

Key words: Glucose, insulin, triglycerides, glucagon, postprandial changes, sex-related differences.
Traditionally stimulation of insulin secretion has been accomplished by using individual nutrients such as glucose or amino acids in large and unphysiological amounts, or by administration of hormones such as glucagon or by administration of pharmacological agents such as tolbutamide. Recently there has been an increasing interest in analysis of B-cell function in physiological states approximating usual daily living conditions. This information should be useful in formulating sound principles for "diabetic diets" and for development of a more physiological insulin regimen.

There have been few studies concerned with the blood glucose and/or plasma insulin response to ordinary meals in human subjects. In 1946, Sindoni [1] reported that the average blood glucose level of 20 normal persons followed for a 4 hour period after a regular breakfast was little changed when compared with the fasting blood glucose. This lack of change in blood glucose was surprising and prompted us to study the plasma glucose and insulin concentrations over an extended period of time in normal human subjects eating three meals a day. Malherbe et al [2] also studied postprandial variations in blood glucose and plasma insulin in normal human subjects. They reported distinct peaks in blood glucose and plasma insulin concentration following each of three standard meals. While our study was in progress, other investigators [3-7] have reported plasma glucose and insulin concentrations following meals but the experimental design was different from that in the present study. In none of the previous studies have the results in men and women been examined independently. In addition we have studied plasma glucagon and triglyceride concentrations following standardized meals. 


\section{Material and Methods}

\section{a. Subjects and Experimental Conditions}

Twelve healthy, human volunteers (seven male and five female) were studied in a Metabolic Unit. One female subject was studied on two separate occasions 20 months apart. All subjects were Caucasian and were within $10 \%$ of ideal body weight using the Metropolitan Life Tables [8]. Mean age, weight and height for the males were 23 years (range 19-26), $169 \mathrm{lbs}$. (range 130-200), and 71 inches (range 69-74) respectively; those for the females were 24 years (range 19-32), $132 \mathrm{lbs}$. (range 114-145) and 66 inches (range 62-68) respectively. They had no known disease or disability and denied taking medication for four months prior to the study. There was no family history of diabetes mellitus. The following laboratory tests were within normal limits: Serum thyroxine, $\mathrm{T}_{3}$ resin uptake, thyroid stimulating hormone, creatinine, urea nitrogen, uric acid, total proteins, albumin, bilirubin, lactic dehydrogenase, glutamic-oxaloacetic acid transaminase, alkaline phosphatase, cholesterol, triglycerides, calcium and phosphorus. All had a normal standard glucose tolerance test [9].

All participants signed an informed consent designed according to the Helsinki agreement on human experimentation and the study was approved by the hospital committee on human studies. The subjects were given a diet consisting of at least $300 \mathrm{~g}$ of carbohydrate per day for three days prior to testing. For the study on the fourth day they were given a diet composed of typical American foods (toast with margarine, bacon, ground beef patty, fruit, sweetened gelatin with whipped cream, cola-type carbonated beverage and coffee), and calculated to contain average proportions of protein, carbohydrate and fat. The total calories administered were based on the recommendations of the National Academy of Sciences [10] considering the differences in body weight, surface area, metabolic rates and energy requirements between males and females. Composition of the diet is shown in Table 1 . The proportion of carbohydrates administered as simple sugars (monosaccharides and disaccharides) to the males and females was 61.3 and 61 percent of the total carbohydrates respectively. The remainder was given as starch. Diets used in other similar studies are shown for comparison. The total calories, protein, carbohydrate and fat were administered as three identical meals, i.e. breakfast, lunch and dinner were identical for each subject. They were served at $8: 30 \mathrm{AM}, 12: 30 \mathrm{PM}$ and $4: 30 \mathrm{PM}$. Subjects were permitted to take their usual time to consume the meals. This ranged from 20 to $30 \mathrm{~min}$. No other food or drinks were allowed except water ad libitum. Smoking was prohibited. The subjects were ambulant during the study; they stayed in a room reading, talking, playing cards or chess, or listening to a radio, except for short walks on the same floor.

Between $7: 30$ and $8: 00 \mathrm{AM}$ after an overnight fast of 8-10 hrs, an indwelling catheter was inserted into an antecubital vein. This was kept open by a syringe containing 100 units of heparin attached to the catheter and $0.5 \mathrm{ml}$ blood aspirated into the syringe. This technique and the rapid frequency of blood sampling helped to keep the catheter open. Heparin was not injected directly into the vein. Five $\mathrm{ml}$ of heparinized venous blood was collected, beginning with two fasting samples at $8: 15$ and $8: 30$ AM then at $2,5,10,20,30,40,50$ and $60 \mathrm{~min}$ after the beginning of each meal for the first hour, every $15 \mathrm{~min}$ for the second hour and every $30 \mathrm{~min}$ for the third hour. In some subjects the 30 min sampling sequence was extended through the fourth hour. The blood samples were centrifuged immediately at $4^{\circ} \mathrm{C}$, plasma separated and stored at $-90^{\circ} \mathrm{C}$ until analysis for glucose, immunoreactive insulin (IRI) and triglycerides. Fasting samples for glucagon and triglycerides were collected at $8: 15$ and $8: 30$ AM and then at $30,60,120$, 180 and 240 (glucagon only) min after each meal. Five $\mathrm{ml}$ of blood for glucagon was collected in chilled glass tubes containing $6 \mathrm{mg}$ of $\mathrm{Na}_{2}$ EDTA and $2500 \mathrm{U}$ trasylol. Samples were centrifuged at $4^{\circ} \mathrm{C}$ and the plasma was divided into three equal aliquots. It was then frozen immediately under dry ice and stored at $-90^{\circ} \mathrm{C}$ until analysis.

\section{b. Assays}

Plasma glucose was determined in duplicate by a glucose oxidase method using a Beckman glucose analyzer (Beckman Instruments, Inc., Fullerton, California). Plasma immunoreactive insulin was measured in duplicate by a standard radioimmunoassay method [11] using insulin antibodies supplied by Pharmacia Laboratories, Inc., Piscataway, N.J. Plasma glucagon was measured by radioimmunoassay [12], using antiserum 30-K, supplied by Dr. Roger Unger; this antiserum is highly specific for pancreatic glucagon but apparently does cross-react with gastric inhibitory polypeptide [13]. Glucagon standards were done in triplicate and the unknowns in duplicate. Plasma triglycerides were measured in duplicate using an automated fluorometric method [14].

Coefficient of variation for plasma glucose assay was $1.5 \%$ for samples in the range of $60-250 \mathrm{mg} / 100$ $\mathrm{ml}$. Coefficient of variation for plasma IRI was $13.4 \%$ for samples in the range of 3-105 $\mu \mathrm{U} / \mathrm{ml}$. For plasma glucagon the coefficient of variation was $3.3 \%$ for 
samples in the range of $35-500 \mathrm{pg} / \mathrm{ml}$ and for triglycerides, $2.1 \%$ in the range of $50-300 \mathrm{mg} / 100 \mathrm{ml}$.

Statistical analysis of the results was done using the student " $t$ " test for paired or unpaired variates as appropriate. The criterion of significance is a $p$ value of $<0.05$.

\section{Results}

\section{a. Males}

The mean plasma glucose concentration (Fig. 1) increased from a fasting level of $95 \mathrm{mg} / 100 \mathrm{ml}$ to a peak value of $143 \mathrm{mg} / 100 \mathrm{ml}$ at $40 \mathrm{~min}$ following breakfast. The peak glucose concentration after lunch and dinner was essentially the same as after breakfast. Plasma glucose concentration returned to the baseline value at $180 \mathrm{~min}$ after breakfast, but this was prolonged to $210 \mathrm{~min}$ after lunch and $240 \mathrm{~min}$ after dinner. A smaller second peak in glucose concentration was noted 60 to $120 \mathrm{~min}$ after each meal.

The increases in plasma insulin in general paralleled very closely those of the plasma glucose in the early post-absorptive period (Fig. 1). However, in the late post-absorptive phase insulin decline was generally slower than the glucose decline. A secondary peak in plasma insulin concentration similar to that for plasma glucose was evident in the late postprandial period after each meal. The concentration of plasma insulin increased from a fasting level of $25 \mu \mathrm{U} / \mathrm{ml}$ to $90 \mu \mathrm{U} / \mathrm{ml}$ at $50 \mathrm{~min}$ following breakfast. Following lunch and dinner the plasma insulin concentration rose to $92 \mu \mathrm{U} / \mathrm{ml}$ in $30 \mathrm{~min}$ and $107 \mu \mathrm{U} / \mathrm{ml}$ in $40 \mathrm{~min}$ respectively. Plasma insulin concentration returned to baseline in 240 min following breakfast, but did not do so by $240 \mathrm{~min}$ following lunch and dinner.

\section{b. Females}

Following breakfast the mean plasma glucose concentration (Fig. 2) increased from a fasting value of 81 $\mathrm{mg} / 100 \mathrm{ml}$ to a peak value of $109 \mathrm{mg} / 100 \mathrm{ml}$ in 30 min, then decreased to below the baseline and remained low until the next meal. The lowest mean plasma glucose concentration reached after breakfast was $63 \mathrm{mg} / 100 \mathrm{ml}$. It represented a fall of $46 \mathrm{mg} / 100$ $\mathrm{ml}$ from the peak glucose concentration. This was not associated with any symptoms or signs of hypoglycemia. Five out of the six studies in females revealed a similar pattern following breakfast.

The peak plasma glucose concentrations following lunch and dinner were 118 and $127 \mathrm{mg} / 100 \mathrm{ml}$ and occurred at 30 and $40 \mathrm{~min}$ respectively. The time taken for the plasma glucose concentration to return to the baseline was approximately $225 \mathrm{~min}$ after breakfast and $240 \mathrm{~min}$ after lunch, whereas, following dinner it had not returned to the baseline by $240 \mathrm{~min}$.

Plasma insulin increased from a fasting value of 14 $\mu \mathrm{U} / \mathrm{ml}$ to a peak value of $90 \mu \mathrm{U} / \mathrm{ml}$ at $50 \mathrm{~min}$ following breakfast. The peak plasma insulin concentrations after lunch and dinner were essentially the same as those seen after breakfast. Plasma insulin concentration returned to baseline $240 \mathrm{~min}$ following breakfast, but had not done so by 240 min following lunch and dinner.

In one female subject the study was prolonged until 12 midnight. Following dinner, plasma glucose

Table 1. Diet analysis

\begin{tabular}{|c|c|c|c|c|c|c|}
\hline & Malherbe & Hansen \& & Schlierf \& & Genuth & Present & study \\
\hline & et al $[2]$ & Johansen [3] & Raetzer [6] & {$[7]$} & Males & Females \\
\hline \multicolumn{7}{|l|}{ Total: } \\
\hline Protein (g) & 90 & 46 & 112 & 90 & 65 & 55 \\
\hline Fat (g) & 75 & 73 & 94 & 81 & 160 & 113 \\
\hline Carbohydrate (g) & 300 & 268 & 261 & 180 & 320 & 210 \\
\hline Alcohol (g) & - & 48 & - & - & - & - \\
\hline Calories & 2235 & 2249 & 2400 & 1800 & 3129 & 2089 \\
\hline \multicolumn{7}{|l|}{$\%$ of Calories: } \\
\hline Protein & 16 & 8 & 19 & 20 & 8 & 10 \\
\hline Fat & 30 & 30 & 36 & 40 & 47 & 48 \\
\hline Carbohydrate & 54 & 48 & 43 & 40 & 45 & 42 \\
\hline Alcohol & - & 14 & - & - & - & - \\
\hline \multicolumn{7}{|l|}{$\%$ of Calories: } \\
\hline Breakfast & 33 & 20 & 33 & 33 & 33 & 33 \\
\hline Lunch & 33 & 23 & 33 & 33 & 33 & 33 \\
\hline Dinner & 33 & 36 & 33 & 33 & 33 & 33 \\
\hline Snacks & - & 21 & - & - & - & - \\
\hline
\end{tabular}


returned to the baseline in $75 \mathrm{~min}$. Between 7 and 12 PM plasma glucose values fluctuated little with a maximum depression below the baseline not exceeding 6 $\mathrm{mg} / 100 \mathrm{ml}$ during this interval. In the same subject the highest plasma insulin value of $101 \mu \mathrm{U} / \mathrm{ml}$ was seen 40 min following dinner, then declined sharply to a level of $21 \mu \mathrm{U} / \mathrm{ml}$ at $60 \mathrm{~min}$ but did not return to baseline for $270 \mathrm{~min}$. Thereafter insulin levels fluctuated modestly until midnight (data not shown).

Table 2 shows mean plasma glucose and insulin peaks computed from the indivudual values irrespective of when these occurred. For males the highest plasma glucose concentration following each meal was similar. For females the peak glucose concentrations following both lunch and dinner were statistically greater than after breakfast $(\mathrm{p}<0.05$ and $<0.02$
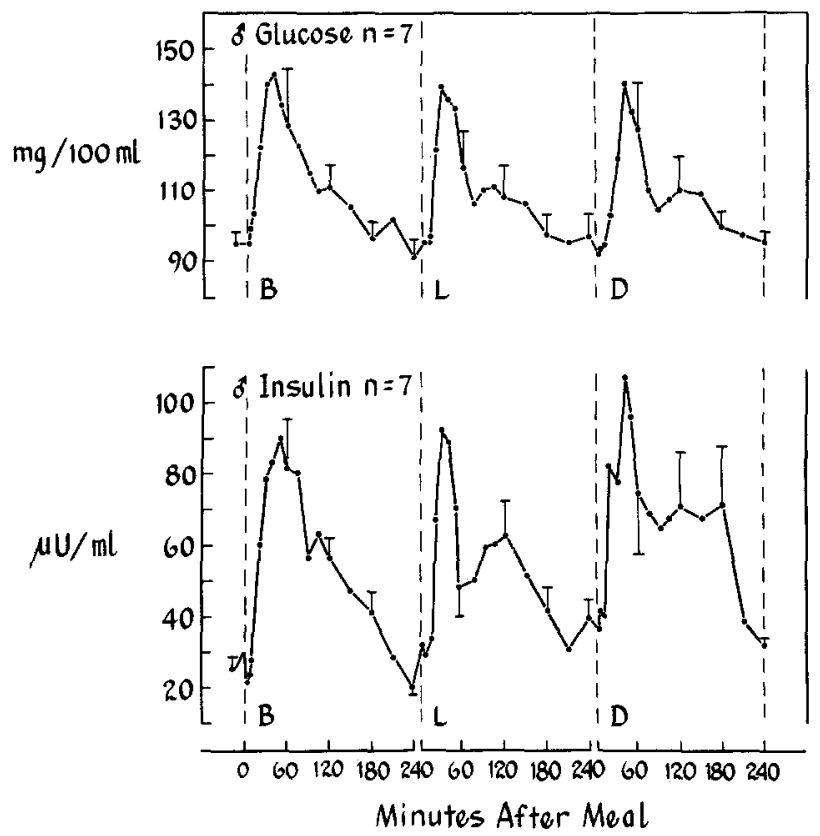

Fig. 1. Postprandial plasma glucose and insulin responses in 7 normal males. Dashed vertical line indicates the beginning of a meal. B (Breakfast), L (Lunch) and D (Dinner). Values are mean \pm SEM respectively). The fasting glucose concentration (not shown in the table) and the highest plasma glucose concentration following meals were both lower in females than in males. The difference in the peaks was significant $(p<0.02)$ after breakfast, but it did not reach statistical significance for the other meals $(p<$ $0.1)$.

There was a gradual increase in the highest postprandial insulin concentration in males as the day progressed; however, these differences were not statistically significant. The postprandial peak insulin concentration was nearly identical for all three meals in the females.

Table 2 also lists areas under the glucose and insulin concentration curves as determined by planimetry and expressed as concentration per min-
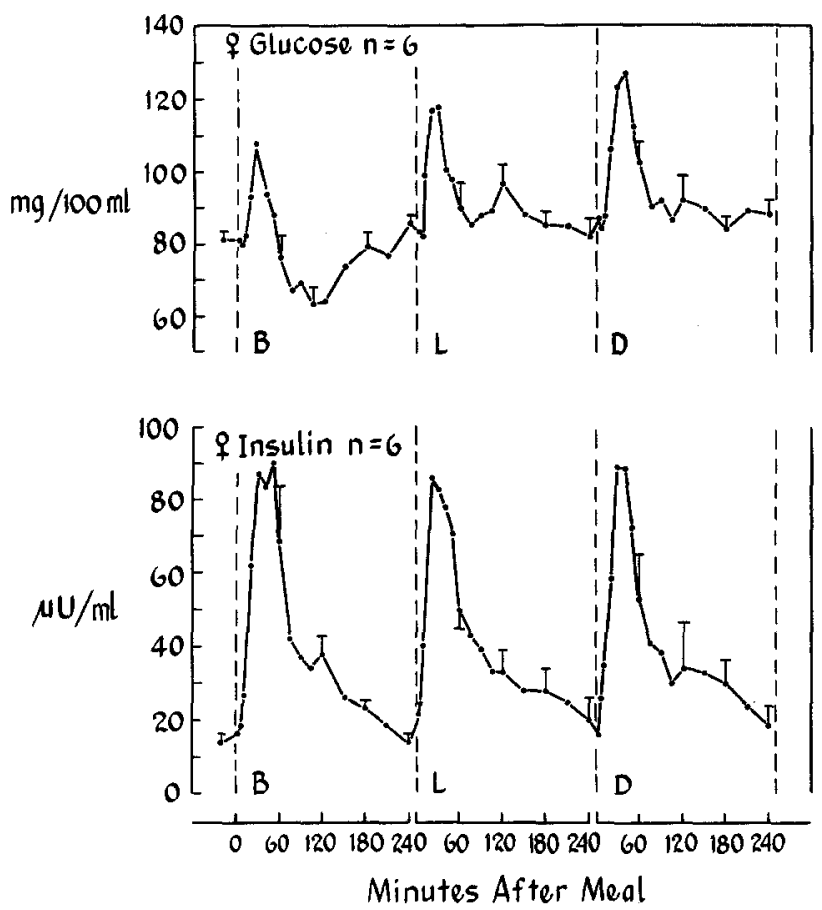

Fig. 2. Postprandial plasma glucose and insulin responses in 5 normal females ( 6 studies). Dashed vertical line indicates the beginning of a meal. B (Breakfast), L (Lunch) and D (Dinner). Values are mean \pm SEM

Table 2. Highest concentrations and areas of glucose and insulin curves postprandially

\begin{tabular}{lllllllll}
\hline & $\begin{array}{l}\text { Peak glucose } \\
\mathrm{mg} / 100 \mathrm{ml}\end{array}$ & \multicolumn{1}{l}{$\begin{array}{l}\text { Peak insulin } \\
\mu \mathrm{U} / \mathrm{ml}\end{array}$} & & \multicolumn{2}{l}{$\begin{array}{l}\text { Glucose area } \\
\mathrm{mg} / 100 \mathrm{ml} / \mathrm{min}\end{array}$} & \multicolumn{2}{l}{$\begin{array}{l}\text { Insulin area } \\
\mu \mathrm{U} / \mathrm{ml} / \mathrm{min}\end{array}$} \\
\hline & Males & Females $^{\mathrm{a}}$ & Males & Females & Males & Females & Males & Females \\
Breakfast & $155 \pm 13$ & $111 \pm 2^{\mathrm{a}}$ & $99 \pm 12$ & $100 \pm 13$ & $1.4 \pm 0.3$ & $-0.2 \pm 0.3^{\mathrm{a}}$ & $2.9 \pm 0.5$ & $2.2 \pm 0.3$ \\
Lunch & $146 \pm$ & $125 \pm 5^{\mathrm{b}}$ & $103 \pm 9$ & $94 \pm 10$ & $1.2 \pm 0.4$ & $1.1 \pm 0.4^{\mathrm{b}}$ & $2.8 \pm 0.3$ & $2.0 \pm 0.3$ \\
Dinner & $145 \pm 9$ & $130 \pm 6^{\mathrm{b}}$ & $126 \pm 16$ & $102 \pm 14$ & $1.1 \pm 0.2$ & $1.2 \pm 0.4^{\mathrm{b}}$ & $3.7 \pm 0.7$ & $2.12 \pm 0.4$ \\
\hline
\end{tabular}

Mean \pm SEM

Males $\mathrm{n}=7$, Females $\mathrm{n}=6$

a Males versus females $p<0.02$ or less

b Significantly different than breakfast $p<0.05$ or less 
ute. For males the area under the glucose curve was essentially the same after each meal; the area under the insulin curve following dinner was greater than that following breakfast or lunch, just as the peak insulin was higher, but again it was not statistically significant $(\mathrm{p}<0.2)$.

For the females, the areas under the glucose curve following both lunch and dinner were significantly greater than after breakfast $(\mathrm{p}<0.02$ and $<0.01$ respectively). However, the areas under the insulin curves remained unchanged after each meal.

The area under the glucose curve following breakfast was below the baseline in females and significantly different $(p<0.01)$ from that of the males. The total area under the plasma insulin curves following meals was greater in males, but this difference did not reach statistical significance $(p<0.1)$.

A quantitative estimate of insulin delivery to the peripheral circulation (excluding insulin removed by the liver on the first pass) was calculated from the integrated plasma insulin areas and the metabolic clearance data reported for normal persons $[15,16]$. It was assumed that the insulin concentration remains low and rather constant during the night $[2,3,5,17]$ and that the metabolic clearance is constant [15-17].
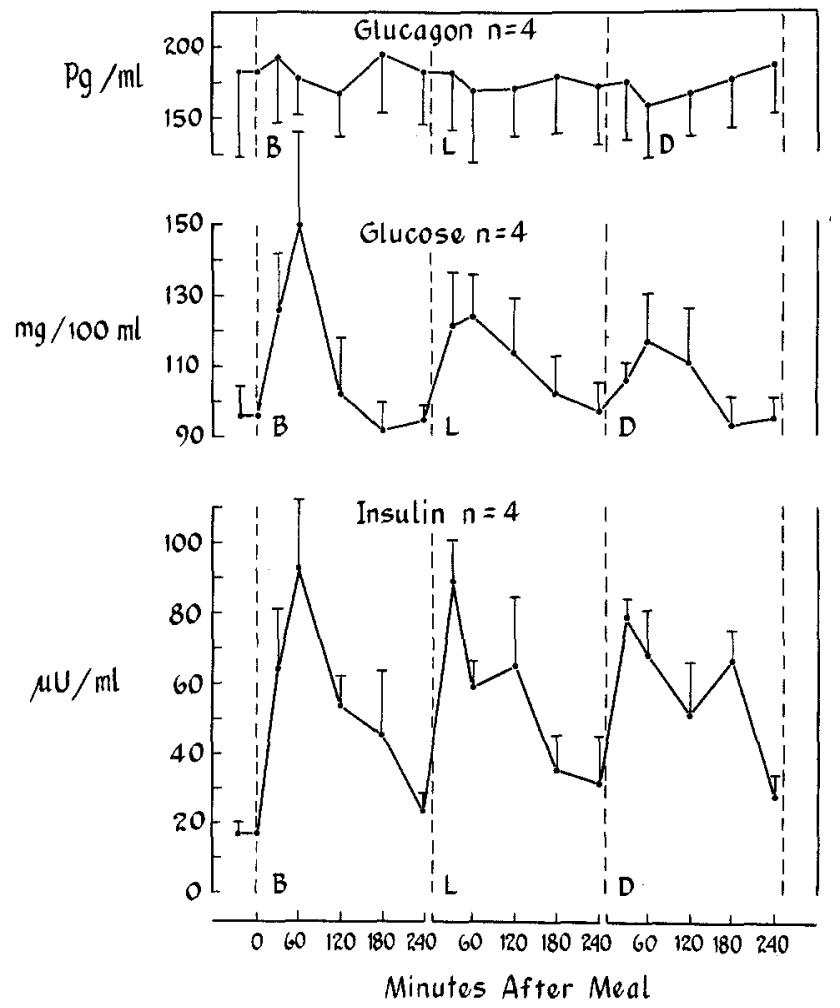

Fig. 3. Postprandial plasma glucagon, glucose and insulin responses in 4 normal subjects ( 2 males and 2 females). Dashed vertical line indicates beginning of a meal. B (Breakfast), L (Lunch) and D (Dinner). Values are mean \pm SEM
For males it was $64 \pm 7.6$ (SEM) units and for females $47 \pm 6.0$ units daily. For all subjects it was $58 \pm 5.0$ units. These results are higher than those reported by Genuth (31 units) and calculated by him [7] from the data of Hansen and Johansen (26 units) [3]. The lower values can be attributed to differences in diet and the relative infrequency of sampling in these studies. The latter would result in an underestimation of insulin areas. A difference in insulin immunoassay method used also could contribute to the discrepancy.

Fig. 3 shows the plasma glucagon concentration in four subjects ( 2 males and 2 females). The mean basal level was $188 \mathrm{pg} / \mathrm{ml}$ and there was very little change throughout the duration of the study. Plasma glucagon concentrations were determined up to midnight in one subject and again there was little change. A significant alteration in plasma insulin/glucagon ( $/ / G)$ ratio was present postprandially and this simply reflected the altered plasma insulin levels.

Plasma triglycerides (Fig. 4) increased after breakfast and remained elevated for the duration of the study in both males and females. There was a suggestion of a rise after both lunch and dinner but these were not significant. Both fasting and postprandial mean triglycerides were higher in males.
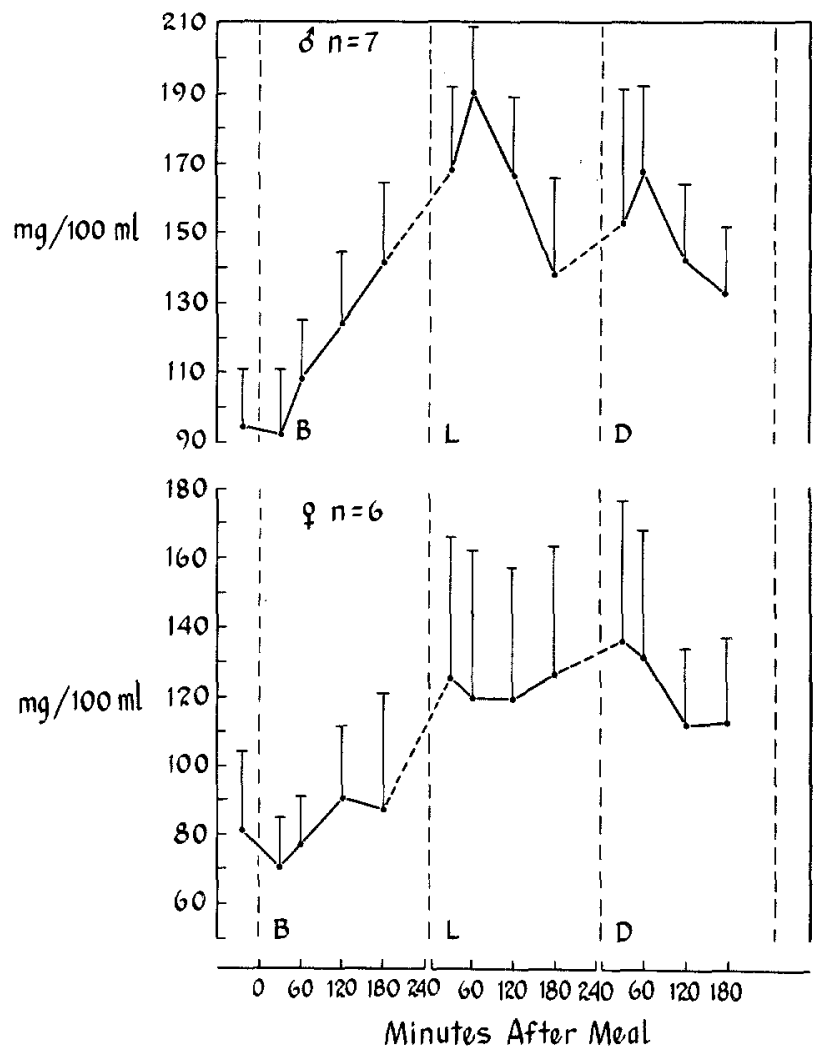

Fig. 4. Postprandial plasma triglyceride responses in 7 males and 5 females ( 6 studies). Dashed vertical line indicates beginning of a meal. B (Breakfast), L (Lunch) and D (Dinner). Values are mean \pm SEM 


\section{Discussion}

The previously reported studies [2-7] of circulating glucose and insulin concentrations following meals have all differed from the present study in regard to meal composition, timing of meals or timing and frequency of blood sampling, making comparison somewhat difficult. However, as in the present study, a significant postprandial rise in plasma glucose and insulin was observed and these were closely related temporally. In the present study there was also a delayed postprandial return of plasma glucose and insulin concentrations to baseline values after lunch and dinner. This appears to be present in other studies, [2, $3,6,7]$ and probably is due to a relative impairment in glucose tolerance late in the day [18].

The rate of rise in glucose and insulin immediately following the beginning of a meal is very rapid and the rise in insulin is proportional to the rise in glucose. Thus it is unlikely that "gut factors"[19] are significantly amplifying the glucose signal at the B-cell to a greater extent at this time than later in the postprandial period. Also a rise in insulin concentration does not occur prior to ingestion of food, even though in some cases, the individuals were not allowed to eat the food placed before them for several minutes. This suggests lack of a "cephalic" phase of insulin secretion mediated through the vagus nerve [20]. In the late postprandial period insulin concentrations were proportionally higher than the glucose values. Review of previously published studies indicates a similar dissociation although it was not commented on by the authors $[2,3,6,7]$. The reason for this dissociation is uncertain. It is possible that factors other than glucose, such as amino acids or "gut factors", are stimulating insulin release at this time. Alternatively it could be due to a lag in response of the B-cells to a declining glucose concentration.

In previous studies males and females were not studied independently. Only Molnar et al., [5] Schlierf and Raetzer [6] and Genuth [7] studied both males and females, but the data were not reported separately. In the present study a considerable difference in glucose and insulin responses was noted between males and females.

The reason for the sex-related differences in glucose and insulin responses after meals is unknown. Estrogen appears to enhance the rate of glucose removal [21] and a sex-related difference in plasma growth hormone level has been described [22, 23]. A difference in muscle mass relative to adipose tissue mass also could play a role. We have previously noted a sex-related difference in muscle glycogen synthase activation $30 \mathrm{~min}$ following glucose or insulin administration, [24] but not at a $60 \mathrm{~min}$ time period (unpublished data). Interestingly Merimee and Tyson [25] have reported considerably lower plasma glucose concentrations in females during a $72 \mathrm{~h}$ fast. The mean glucose concentration also was lower in the females in the present study.

The circulating pancreatic glucagon concentration was unaffected by meals and remained stable throughout the day (Fig. 3). Hansen and Johansen [3] using an antibody which does not distinguish between gut and pancreatic glucagon have also reported little change in serum glucagon during a 24-hour period in three subjects fed a standard diet. Ingestion of a mixture of amino acids or a protein meal results in a rise in serum glucagon [26, 27] and ingestion of large amounts of glucose lowers the plasma glucagon concentration [28]. The lack of postprandial change in glucagon concentration in the present study possibly reflects the opposing influence of proteins and carbohydrates on pancreatic glucagon secretion. In normal individuals fed a high protein diet a rise in plasma glucagon occurs and it continues to increase throughout the day (unpublished observations).

Schlierf and Raetzer [6] have reported peaks in plasma triglyceride concentrations 5-6 hrs following a standard meal, resulting in approximate doubling of fasting triglyceride values, as was observed in the present study. In fat loading experiments triglyceride values have been reported to be higher in males than in females [29]. In the present study the mean triglyceride concentration was higher in males, both fasting and after meals, although none of these differences were significant due to the great variability found. In both sexes there was a gradual rise throughout the day.

Acknowledgement. We acknowledge with gratitude the cooperation of our volunteers. We greatly appreciate the technical assistance of Miss Rita Lamusga and Mrs. Nancy Anderson and the assistance of Miss Jean Wald (research dietitian) for calculation of the diets. We wish to thank the staff of the Special Diagnostic and Treatment Unit for their assistance with the study and Mrs. Sherrie Regel for help in preparing this manuscript.

\section{References}

1. Sindoni, A.: Fasting blood sugar vs. postprandial blood sugar as observed in normal individuals, medical (non-diabetic) patients, and patients with diabetes. Amer. J. dig. Dis. 13, 178-192 (1946)

2. Malherbe, C., DeGasparo, M., DeHertogh, R., Hoet, J.J.: Circadian variations of blood sugar and plasma insulin levels in man. Diabetologia 5, 397-404 (1969)

3. Hansen, Aa.P., Johansen, K.: Diurnal patterns of blood glu- 
cose, serum free fatty acids, insulin, glucagon and growth hormone in normals and juvenile diabetics. Diabetologia 6, 27-33 (1970)

4. Molnar, G.D., Ackerman, E., RoseVear, J.W., Gatewood, L.C., Moxness, K.E.: Continuous blood glucose analysis in ambulatory fed subjects. I. General methodology. Mayo Clin. Proc. 43, 833-851 (1968)

5. Molnar, G.D., Taylor, W.F., Longworthy, A.L.: Plasma immunoreactive insulin patterns in insulin-treated diabetics. Studies during continuous blood glucose monitoring. Mayo Clin. Proc. 47, 709-719 (1972)

6. Schlierf, G., Raetzer, H.: Diurnal patterns of blood sugar, plasma insulin, free fatty acids and triglyceride levels in normal subjects and in patients with Type IV hyperlipoproteinemia and the effect of meal frequency. Nutr. Metab. 14, 113-126 (1972)

7. Genuth, S. M.: Plasma insulin and glucose profiles in normal, obese, and diabetic persons. Ann. intern. Med. 79, 812-822 (1973)

8. New weight standards for men and women. Statistical bulletin, Metropolitan Life Insurance Co. 40, 1 (1959)

9. Fajans, S.S., Conn, J.W.: Early recognition of diabetes mellitus. Ann. N. Y. Acad. Sci. 82, 208-218 (1959)

10. Recommended dietary allowances, recommendations of food and nutrition board, Seventh Edition. Washington, D. C.: National Academy of Sciences - National Research Council 1968

11. Yalow, R.S., Berson, S. A.: Immunoassay of endogenous plasma insulin in man. J. clin. Invest. 39, 1157-1175 (1960)

12. Aguilar-Parada, E., Eisentraut, A. M., Unger, R. H.: Pancreatic glucagon secretion in normal and diabetic subjects. Amer. J. med. Sci. 257, 415-419 (1969)

13. Vranic, M., Pek, S., Kawamori, R.: Increased "glucagon immunoreactivity" in plasma of totally depancreatized dogs. Diabetes 23, 905-912 (1974)

14. Noble, R.P., Campbell, F.M.: Improved accuracy in automated fluorometric determination of plasma triglycerides. Clin. Chem. 16, 166-170 (1970)

15. Genuth, S.M.: Metabolic clearance of insulin in man. Diabetes 21, 1003-1012 (1972)

16. Sonksen, P.H., Tompkins, C. V., SriVastava, M.C., Nabarro, J.D.N.: Growth-homone and cortisol responses to insulin infusion in patients with diabetes mellitus. Lancet 1972 II, 155-159

17. Chu, P-C., Conway, M.J., Krouse, H. A., Goodner, C. J.: The pattern of response of plasma insulin and glucose to meals and fasting during chlorpropamide therapy. Ann. intern. Med. 68, 757-769 (1968)

18. Carroll, K.F., Nestel, P.J.: Diurnal variation in glucose toler- ance and in insulin secretion in man. Diabetes 22, 333-348 (1973)

19. Chisholm, D.J., Young, J.D., Lazarus, L.: Gastrointestinal stimulus to insulin release. J. clin. Invest. 48, 1453-1460 (1969)

20. Goldfine, I.D., Abraira,C., Gruenewald, D., Goldstein, M. S.: Plasma insulin levels during imaginary food ingestion under hypnosis. Proc. Soc. exp. Biol. (N.Y.) 133, 274-276 (1970)

21. Tyson, J.E., Austen, K., Fairholt, J.: Estrogen modulation of glucose homeostasis. Clin. Res. 22, 481 (1974)

22. Frantz, A. G., Rabkin, M. T.: Effects of estrogen and sex differences on secretion of human growth hormone. J. clin. Endocr. 25, 1470-1480 (1965)

23. Merimee, T.J., Rabinowitz, D., Fineberg, S.E.: Arginine initiated release of human growth hormone. New Engl. J. Med. 280, 1434-1438 (1969)

24. Nuttall, F. Q., Barbosa, J., Gannon, M.C.: The glycogen synthase system in skeletal muscle of normal humans and patients with myotonic dystrophy: Effect of glucose and insulin administration. Metabolism 23, 561-568 (1974)

25. Merimee, T.J., Tyson, J.E.: Stabilization of plasma glucose during fasting. New Engl. J. Med. 291, 1275-1278 (1974)

26. Ohneda, A., Parada, E., Eisentraut, A. M., Unger, R.: Characterization of response of circulating glucagon to intraduodenal and intravenous administration of amino acids. J. clin. Invest. 47, 2305-2322 (1968)

27. Müller, W.A., Faloona, G.R., Aguilar-Parada, E., Unger, R.H.: Abnormal alpha-cell function in diabetes. Response to carbohydrate and protein ingestion. New Engl. J. Med. 283, 109-115 (1970)

28. Unger, R.H., Eisentraut, A.M.: Studies of the physiologic role of glucagon. Diabetes 13, 563-568 (1964)

29. Shah, S., Pomeroy, V., Michaels, G., Coehlo, M., Kinsell, L. W.: Glyceride and fatty acid response to fat loading in normal and abnormal subjects. Metabolism 12, 887-898 (1963)

Received: August 8, 1975, and in revised form: December 15, 1975

M. Ahmed, M.D.

Metabolic-Endocrine Section

Assistant Professor

Dept of Medicine Veterans

Administration Hospital

54th Street and 48th Avenue South

Minneapolis, Minnesota 55417

USA 